\title{
Optimal robust stabilizer design based on UPFC for interconnected power systems considering time delay
}

\author{
HAMID REZa KOOFIGAR, GHADER ISAZADEH \\ Department of Electrical Engineering, University of Isfahan \\ Isfahan 81746-73441, Iran \\ e-mail:koofigar@eng.ui.ac.ir
}

(Received: 30.12 .2015 , revised: 25.04.2017)

\begin{abstract}
A robust auxiliary wide area damping controller is proposed for a unified power flow controller (UPFC). The mixed $\mathrm{H}_{2} / \mathrm{H}_{\infty}$ problem with regional pole placement, resolved by linear matrix inequality (LMI), is applied for controller design. Based on modal analysis, the optimal wide area input signals for the controller are selected. The time delay of input signals, due to electrical distance from the UPFC location is taken into account in the design procedure. The proposed controller is applied to a multimachine interconnected power system from the IRAN power grid. It is shown that the both transient and dynamic stability are significantly improved despite different disturbances and loading conditions.
\end{abstract}

Key words: UPFC, mixed $H_{2} / H_{\infty}$, LMI, wide area, power system oscillations, time delay

\section{Introduction}

Undamped inter-area oscillation with frequencies in the range of $0.1-1 \mathrm{~Hz}$ has become one of the major problems in power transmission between areas in modern interconnected power systems. The conventional power system stabilizers (PSSs), limited to some specified modes and loading conditions, does not present an acceptable dynamic performance at different operating points and disturbances [1-2]. Removing such drawback, application of FACTS devices has been shown to be an effective and practical strategy for stability enhancement [3]. The UPFC from the FACTS family has been also introduced as a device with the ability of controlling both the active and reactive power independently and simultaneously [4].

It is well-known that the conventional PI controller design based on the linearized model of the system does not ensure an acceptable performance in all system conditions [5-6]. Some auxiliary robust stabilizing signals may be incorporated into the UPFC series controller to provide a feasible solution for stability enhancement [7-8]. An $H_{\infty}$ mixed sensitivity approach 
can be applied to damping controller design for the UPFC [9] and a comparison has been made between the performance of $H_{\infty}$ algorithm and $\mu$-synthesis, developed for the SVC, in the presence of disturbances [10]. Using the LMI approach with $H_{\infty}$ loop shaping, a robust PSS design can be constructed [11]. Of course, a multi-objective synthesis, formed by both the time and frequency domain specifications from $H_{2}$ and $H_{\infty}$ performance, may present more advantages over a single objective function $[12,13]$. Nevertheless, all of the cited controllers ignore the time delay, due to the measured input wide area signals. However, it has been shown that time delays could have an adverse effect in wide area damping controller (WADC) performance [14] or degrade dynamic performance of load frequency control (LFC) schemes [15]. Evaluating a fixed robust control design, at various time delays, shows that the performance is highly dependent to such input delays [14-16].

Removing the aforementioned drawbacks, in this paper, a novel optimal wide area damping controller of the UPFC is proposed considering wide area signals measuring time delays. The mixed $\mathrm{H}_{2} / \mathrm{H}_{\infty}$ problem is proposed for design the UPFC controller and the regional pole placement is applied and resolved by the LMI approach to have the desire damping at different conditions and disturbances. Based on modal analysis, the effective wide area input signals for the proposed controller are selected with respect to maximum observability for each of determined critical inter-area modes. The proposed controller is then applied to an allocated UPFC in the large multi-machine interconnected three area power system from IRAN transmission power grid. These areas include the Tehran Regional Electrical Company (TREC), Esfahan Regional Electrical Company (EREC) and Khuzestan Regional Electrical Company (KhREC) with their practical damping problems and inter-area oscillations. The wide area signal time delays are taken into account and the stability of the closed loop system is investigated at different operating conditions and disturbances. Dynamic response of the proposed method is then compared with that of the $H_{\infty}$ damping and no damping (only conventional PI series and shunt) controllers. It is shown that the application of the designed controller for the allocated UPFC can effectively improve the system stability and damping of inter-area oscillations at different conditions and time delays.

\section{Stability enhancement via unified power flow controller}

\subsection{UPFC structure}

The structure of a UPFC, with the ability to control the both active and reactive power independently and simultaneously, consists of the shunt and series inverters, connected through a dc capacitor, as shown in Fig. 1 [4]. By controlling the magnitude and the phase of the series injected voltage $\left(\boldsymbol{U}_{\text {ser }}\right)$, the real and reactive power flow in the transmission line can be managed. The shunt inverter provides the required active power for the series branch and the UPFC losses. Also, the reactive compensation to maintain the shunt bus voltage at the defined set point is performed by the shunt inverter [3-5]. 


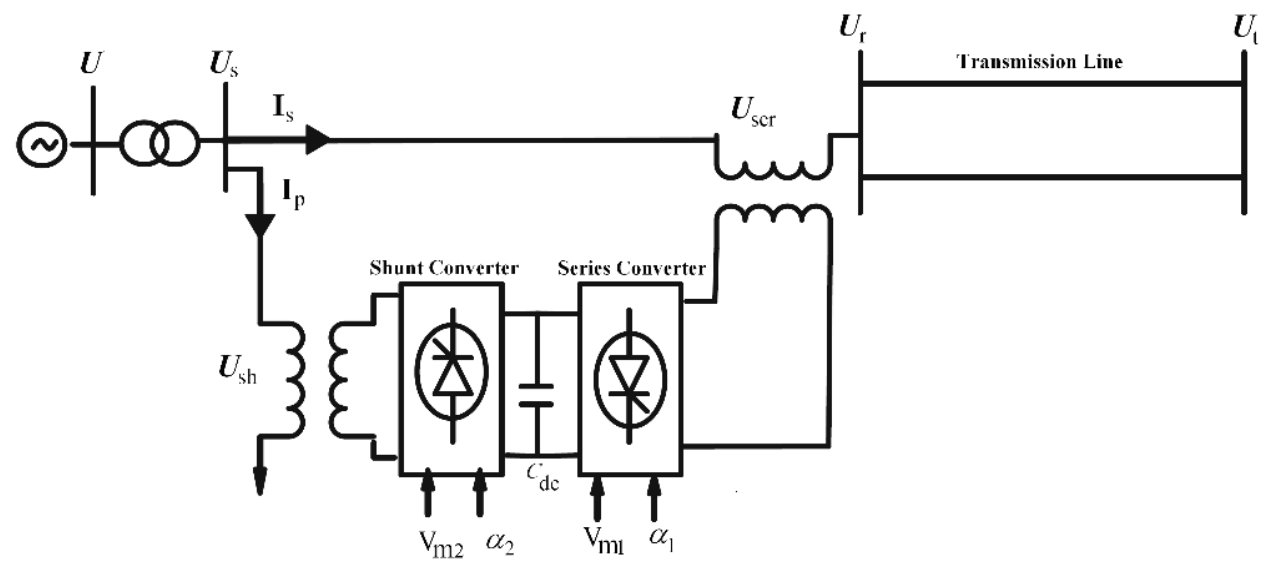

Fig. 1. UPFC structure and its connection in power system

\subsection{UPFC damping controller}

Stability enhancement could be achieved by fast changing the active and reactive power flow in the transmission line by controlling the series injected voltage of a UPFC [8]. The simple conventional PI controllers, designed based on the linearized model of the system at the certain operating points, do not provide an appropriate dynamic response to various loading conditions and disturbances [6]. It can be shown that adding optimal robust auxiliary damping signals to the conventional PI controllers, is the effective strategy for stability enhancement [13]. The block diagram of the conventional PI and its damping controller for the series branch of the UPFC is shown in Fig. 2. The PI controller is based on the P-Q decoupled method and the series controller outputs are the modulation index $\left(V_{m 1}\right)$ and the phase shift $\left(\alpha_{1}\right)$ [17]. The shunt branch of the UPFC is controlled by two similar PI controllers to generate the related modulation index and phase shift to control the ac and dc bus voltages. Hence, in this study, the appropriate optimal supplementary damping signals $P_{c}$ and $Q_{c}$ are proposed.

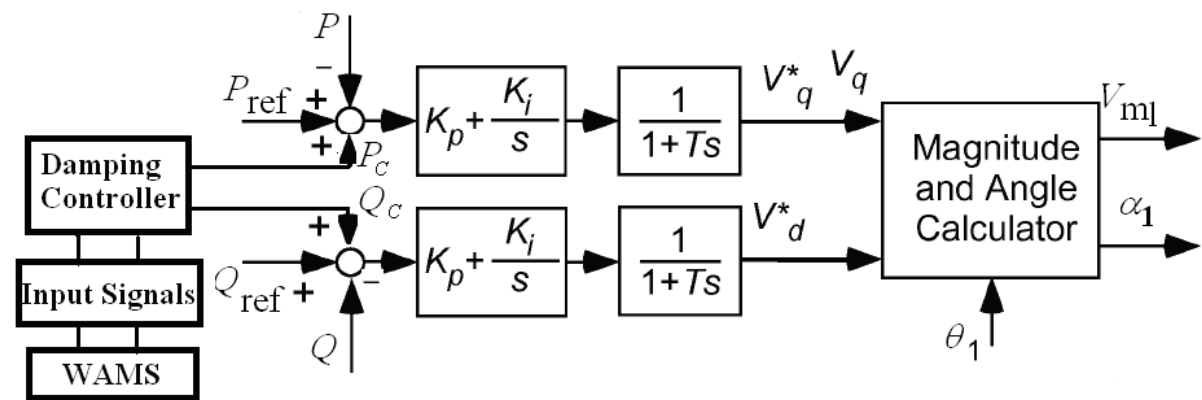

Fig. 2. Damping controller for the series branch of UPFC 


\section{Multi-objective $\boldsymbol{H}_{2} / \boldsymbol{H}_{\infty}$ damping controller}

It is well known that the $H_{\infty}$ control is mainly concerned with frequency domain and does not necessarily guarantee good transient performance [18]. Also, in $H_{\infty}$ control synthesis, there exist some conflicts between various weighting functions selection [12-14]. On the other hand, the $\mathrm{H}_{2}$ control algorithm presents a more suitable performance on system transient behavior. Thus, to overcome the limitation of a single objective technique, a multi-objective technique is adopted for the UPFC damping controller, as depicted in Fig. 3. The outputs $Z_{\infty}$ and $Z_{2}$ are associated with the $H_{\infty}$ and $H_{2}$ performance, respectively. The weighting function $W_{1}(s)$ is a low-pass filter, dealing with $H_{2}$ performance for disturbance rejection, $W_{2}(s)$ is a high-pass filter to reduce control effort, and $W_{3}(s)$ is also a high-pass filter associated with $H_{\infty}$ performance to ensure robustness against model uncertainties [12]. In the proposed scheme, the $H_{\infty}$ performance is used to measure the robustness against dynamic uncertainty, while the $\mathrm{H}_{2}$ performance is used to measure control effort and disturbance attenuation [12].

\subsection{LMI-based $\boldsymbol{H}_{2} / \boldsymbol{H}_{\infty}$ with regional pole placement}

The constructed multi-objective problem can be solved by the LMI technique [19]. It is shown that the LMI approach facilitates solving the control problems without pole-zero cancellation [20]. Furthermore, a minimum damping ratio $\xi=\cos \theta$ is guaranteed, by placing all the closed loop poles in the desired left half s-plane, as shown in Fig. 4.

\subsection{Delay dependent stability analysis}

Since for a large power system, the primary order of the linearized model is commonly high, a model reduction method is applied. In this paper, the Schur model reduction method from the MATLAB software package is used to reduce the order of the full order model [21]. The model of the closed loop power system including the reduced order power system and its wide area damping controller with respect to Fig. 5 can be represented as [22]:

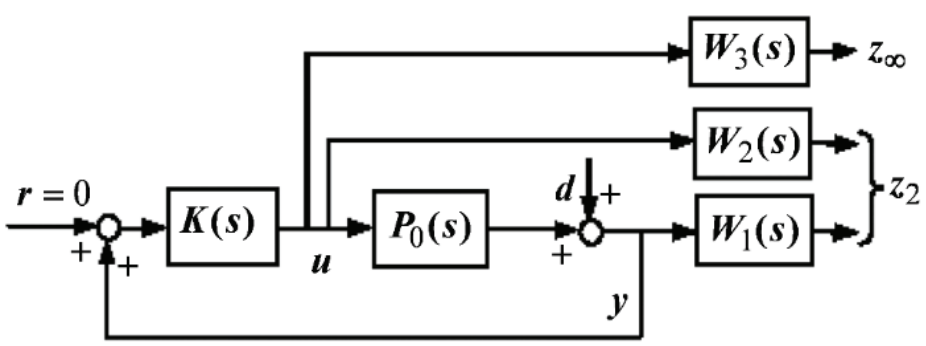

Fig. 3. Multi-objective controller synthesis

$$
\dot{\boldsymbol{x}}(t)=\boldsymbol{A} \boldsymbol{x}(t)+\boldsymbol{A}_{d} \boldsymbol{x}(t-d(t)),
$$




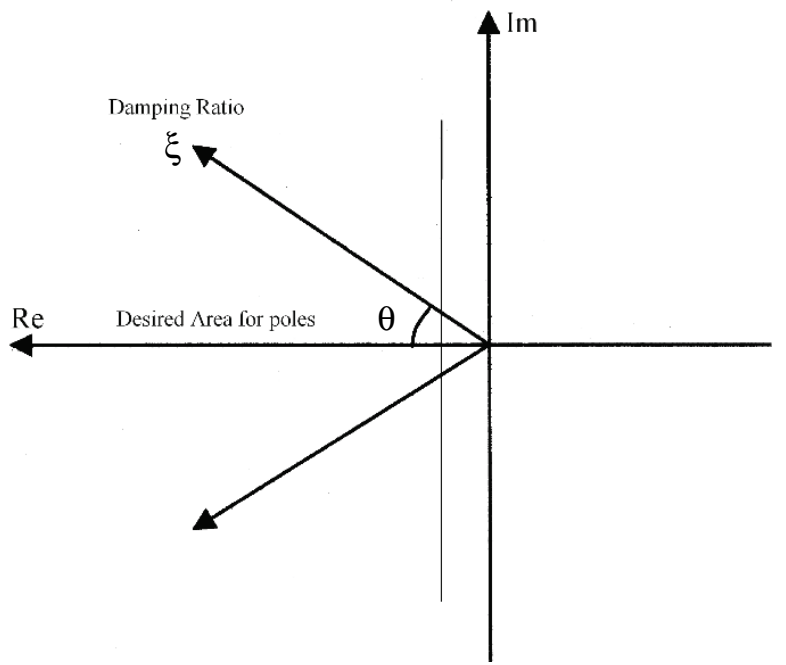

Fig. 4. LMI region for desired pole placement

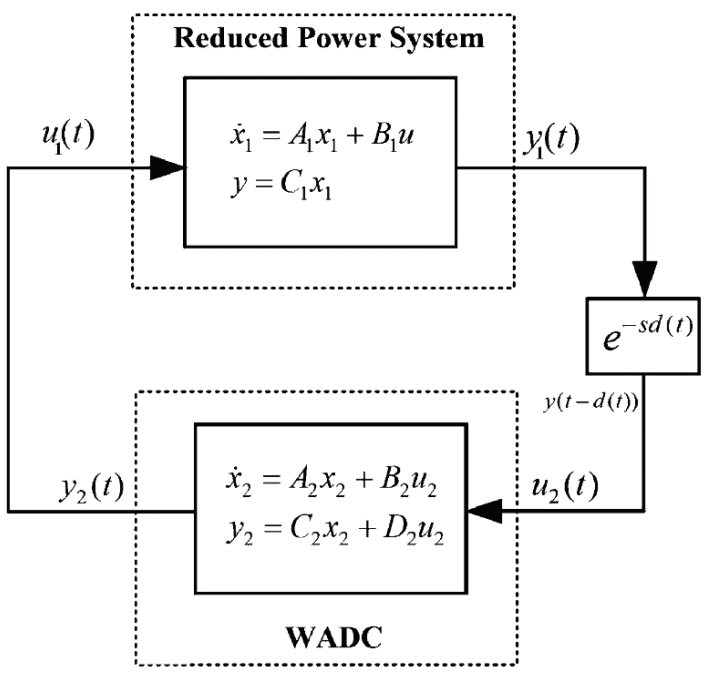

Fig. 5. Wide area damping controller (WADC)

in which

$$
\begin{aligned}
A_{d} & =\left[\begin{array}{ll}
B_{1} D_{2} C_{1} & 0 \\
B_{2} C_{1} & 0
\end{array}\right], \\
A & =\left[\begin{array}{ll}
A_{1} & B_{1} C_{2} \\
0 & A_{2}
\end{array}\right]
\end{aligned}
$$


and

$$
\boldsymbol{x}=\left[\boldsymbol{x}_{1}, \boldsymbol{x}_{2}\right]^{T} .
$$

By Fig. 5, the reduced order model and the damping controller are connected by:

$$
\begin{aligned}
& \boldsymbol{u}_{2}(t)=y_{1}(t-d(t)), \\
& \boldsymbol{u}_{1}(t)=y_{2}(t)
\end{aligned}
$$

and $d(t)$ represents the time varying delay.

\subsection{Delay dependent stability criterion}

Many Lyapunov based methods have been investigated for time delay margin calculation with different levels of conservation [23]. In this paper, the free weighting matrices methods, proposed in [24], with less conservativeness has been applied. Consider a system with timevarying delay as

$$
\left\{\begin{array}{l}
\dot{\boldsymbol{x}}(t)=\boldsymbol{A} \boldsymbol{x}(t)+\boldsymbol{A}_{d}(\boldsymbol{x}(t-d(t)) \\
\boldsymbol{x}(t)=\boldsymbol{\varphi}(t) \quad t \in[-\tau, 0]
\end{array}\right.
$$

where $\boldsymbol{\varphi}(t)$ is a continuous vector-valued initial function of $t \in[-\tau, 0]$, and $d(t)$ is a timevarying continuous function that satisfies [25]:

$$
0 \leq d(t) \leq \tau \quad|\dot{d}(t)| \leq \mu \leq 1 .
$$

In (7), $\tau$ and $\mu>0$ are constants and initial conditions. The following theorem is used for the stability of linear system with time delay.

Theorem. The time-delayed system described by (6) is asymptotically stable if there exist the symmetric positive definite matrices $\boldsymbol{P}=\boldsymbol{P}^{T}>\mathbf{0}, \boldsymbol{Q}=\boldsymbol{Q}^{T_{>}} \mathbf{0}, \boldsymbol{Z}=\boldsymbol{Z}^{T_{>}} \mathbf{0}$, and a symmetric semi positive definite matrix

$$
\begin{aligned}
\boldsymbol{X} & =\left[\begin{array}{ll}
\boldsymbol{X}_{11} & \boldsymbol{X}_{12} \\
\boldsymbol{X}_{12}^{T} & \boldsymbol{X}_{22}
\end{array}\right] \geq 0 \text { such that the following LMIs are satisfied: } \\
\Phi & =\left[\begin{array}{lll}
\boldsymbol{\Phi}_{11} & \boldsymbol{\Phi}_{12} & \tau \boldsymbol{A}^{T} \boldsymbol{Z} \\
\boldsymbol{\Phi}_{12}^{T} & \boldsymbol{\Phi}_{22} & \tau \boldsymbol{A}_{d}^{T} \boldsymbol{Z} \\
\tau \boldsymbol{Z} \boldsymbol{A} & \tau \boldsymbol{Z} \boldsymbol{A}_{d} & -\tau \boldsymbol{Z}
\end{array}\right]<0, \Psi=\left[\begin{array}{lll}
\boldsymbol{X}_{11} & \boldsymbol{X}_{12} & \boldsymbol{Y} \\
\boldsymbol{X}_{12}^{T} & \boldsymbol{X}_{22} & \boldsymbol{T} \\
\boldsymbol{Y}^{T} & \boldsymbol{T}^{T} & \boldsymbol{Z}
\end{array}\right] \geq 0,
\end{aligned}
$$

where $\boldsymbol{Y}$ and $\boldsymbol{T}$ have the appropriate dimensions and $\boldsymbol{\Phi}_{11}, \boldsymbol{\Phi}_{12}$ and $\boldsymbol{\Phi}_{22}$ are defined in [24].

Remark. For time-invariant delay systems, $\boldsymbol{X}_{12}, \boldsymbol{X}_{12}$ and $\boldsymbol{T}$, in above LMIs, are set to zero. 


\section{Wide area damping controller design procedure}

The first step to the wide area damping controller design is power system modeling includeing generators, AVR, Governor, loads and other equipment. The other main steps in controller design are as follows:

1) Linearization and input selection: The full order system is linearized at specified loading conditions to determine the critical inter-area modes, using modal analysis. Also, to have an optimal performance, the signals with maximum observability are determined for each of the critical modes for controller input selection, based on the performed geometric analysis [26]. Then, the Schur method from the LMI toolbox in MATLAB software is used for model reduction [21].

2) UPFC allocation: Based on the defined security index in the studied interconnected power system, the optimal location for the UPFC is determined. The UPFC capacity is assumed to be 100 MVA for each shunt and series converter.

3) Controller synthesis: The mixed $H_{2} / H_{\infty}$ output feedback control with regional pole placement, considering time delays for input signals, is applied to design the WADC [27] in the reduced order model of the original linearized power system. The determined controller order is reduced again with a balanced model reduction scheme.

4) Eigenvalue analysis and time domain simulation: By performing the small signal stability analysis at different conditions, robustness of the proposed method is investigated. The dynamic performance of the proposed method for the allocated UPFC is compared with that of the optimized PI and $H_{\infty}$ methods by time domain simulation.

\section{Iran national power grid and operation problems}

The IRAN transmission power grid is a widespread network in five basic areas with several long and heavy loaded $400 \mathrm{kV}$ and $230 \mathrm{kV}$ tie-lines to transmit more than $64000 \mathrm{MW}$ installed generation capacity [28].

The $400 \mathrm{kV}$ interconnected power system between TREC, EREC and the KhREC is shown in Fig. 6. In practice, there are two main problems in the $400 \mathrm{kV}$ network of the Iran power grid, especially between the highlighted areas in Fig. 6 which are normally heavy loaded tielines: (i) the tie-lines loading limit and voltage consideration in an outage condition of tie-lines which could result in a cascade outage of tie lines because of relay operations, and (ii) undamped or poor inter-area oscillations between areas in different contingencies in a high power transmission level between areas, which lead to system separation and wide area outages. Therefore, several operational limits are applied in tie-lines power flows between these areas, which make actual power flows in these lines to be so far from their thermal limits.

To overcome the aforementioned problems, balancing and also increasing the power flows in these tie lines, the IRAN grid management company (IGMC) has been decided to study the possibility of UPFC application in the appropriate location in these corridors. The static and 
dynamic data of the IRAN power network including generators and their exciter and governor models have been given in [28].

\section{UPFC allocation}

The initial purpose of the UPFC application is control of the active and reactive power flow as well as voltage support at $400 \mathrm{kV}$ tile lines between the mentioned areas. The UPFC location is determined based on the composite severity index investigation in different contingencies in the power system under consideration [29]. The overall index consists of three different indices including line loading, bus voltage violation and voltage stability. Through various simulations for interconnected tie-lines between these areas, the suitable location for UPFC installation is found to be at 1-36 tie-line in Fig. 6. The UPFC active power set point is set to transmit $375 \mathrm{MW}$ power from TREC to the KhREC from this line while the previous power flow was $112 \mathrm{MW}$.

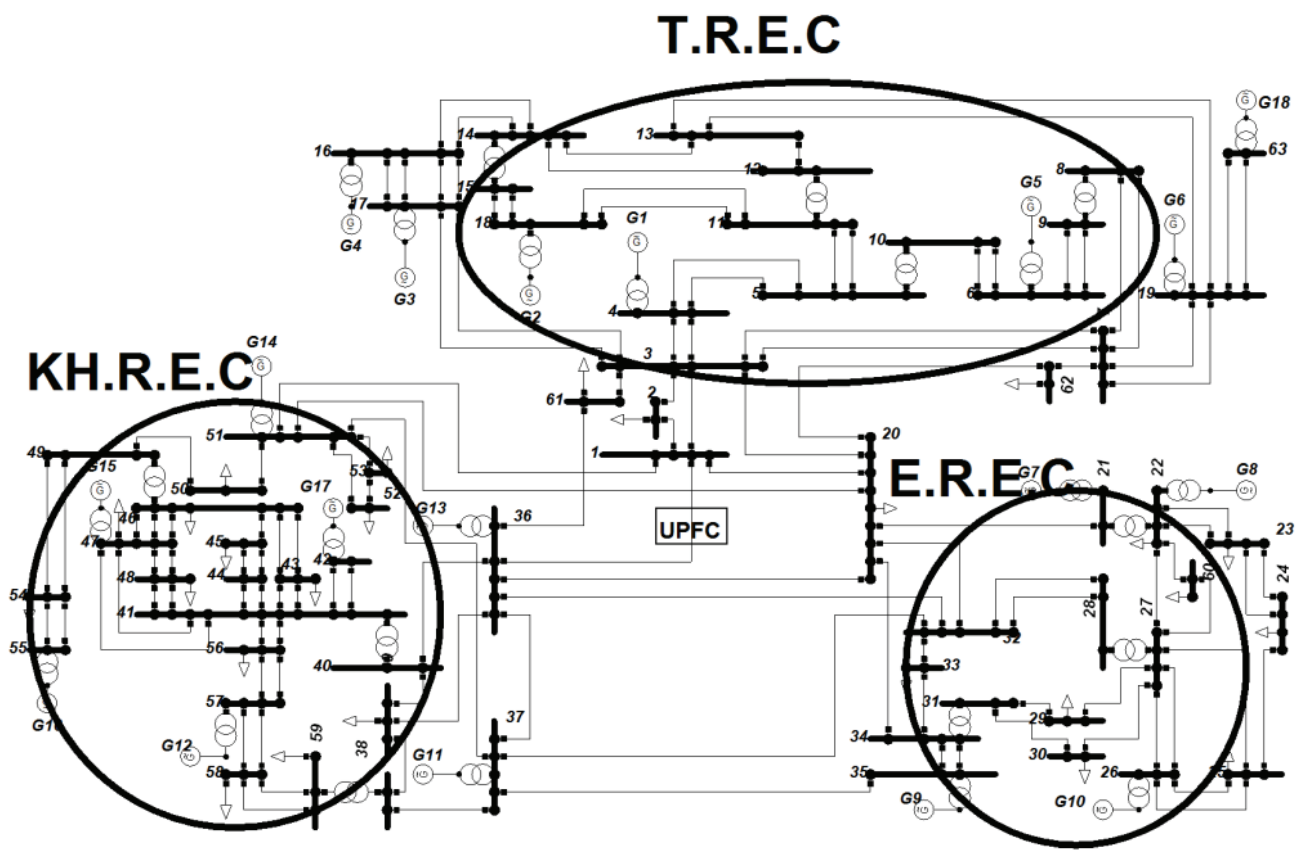

Fig. 6. TREC, EREC and KhREC transmission network in IRAN power grid

\section{Simulation study}

In this section, the proposed controller is implemented at the installed UPFC. 


\subsection{Linearization, input selection and model reduction}

The Digsilent power factory software is used for modeling the studied network and modal analysis, linked to MATLAB to perform different necessary analysis such as model order reduction through Digsilent programming language (DPL). The critical inter-area modes and their damping ratios at 1600 MVA power transmission form TREC to other two regions based on linearized equations of the full order model is shown in Table 1. The linearized system is of order 188 and should be reduced to facilitate controller design. Based on geometric analysis, the related signals with maximum observability to each of critical modes are selected as the controller inputs, as reported in Table 2.

The active power flows in four transmission lines, specified in Table 2, are selected as inputs and $P_{C}$ as well as $Q_{C}$ in Fig. 2 are defined as the controlled outputs. The order of a linearized model is reduced from 188 to 8 by the Schur method. The frequency response of both the original and the reduced order model are shown in Fig. 7, by choosing active power of line 1-16 as input and $P_{C}$ of the damping controller as output.

Table 1. Critical inter-area modes and the damping ratios at 1600 MVA with no controller

\begin{tabular}{c|c|c}
\hline \multirow{2}{*}{ Mode index } & \multicolumn{2}{|c}{ No controller in $\mathbf{1 6 0 0} \mathbf{M}$} \\
\cline { 2 - 3 } & $\xi$ & $f(\mathrm{~Hz})$ \\
\hline 1 & 0.0272 & 0.653 \\
\hline 2 & 0.0175 & 0.488 \\
\hline 3 & 0.0282 & 0.425 \\
\hline 4 & 0.0154 & 0.379 \\
\hline
\end{tabular}

Table 2. Parameters with maximum observability for each critical mode

\begin{tabular}{c|c|c}
\hline $\begin{array}{c}\text { Mode } \\
\text { index }\end{array}$ & Mode shape & Maximum observability \\
\hline 1 & $(\mathrm{G} 7, \mathrm{G} 8)$ vs $(\mathrm{G} 1, \mathrm{G} 2, \mathrm{G} 3, \mathrm{G} 4)$ & $I_{20-21}, P_{20-21}$ \\
\hline 2 & $\mathrm{G} 11$ vs $(\mathrm{G} 9, \mathrm{G} 10)$ & $I_{37-32}, P_{37-32}$ \\
& & $\omega_{11-9}$ \\
\hline 3 & $(\mathrm{G} 6, \mathrm{G} 5)$ vs $(\mathrm{G} 11, \mathrm{G} 12, \mathrm{G} 13)$ & $I_{1-36}, P_{1-36}$ \\
\hline 4 & $(\mathrm{G} 14, \mathrm{G} 15, \mathrm{G} 16)$ vs $(\mathrm{G} 9, \mathrm{G} 10),(\mathrm{G} 7, \mathrm{G} 8)$ & $I_{36-20}, P_{36-20}$ \\
\hline
\end{tabular}

The LMI toolbox from the MATLAB package is used for controller synthesis [26]. The minimum damping ratio and minimum rate of decay are set to be 0.25 and 0.4 , respectively. It is shown that the selection of weighting functions in the following form has the advantage of a larger time delay margin compared with the constant value selection for $W_{2}$ [14]. The computed margins for the considered time delays at different $W_{2}$ functions are given in Table 3.

$$
W_{1}(s)=\frac{50}{s+50}, \quad W_{3}(s)=\frac{100 s}{s+100}, \quad W_{2}(s)=\frac{0.5 s}{s+50} .
$$




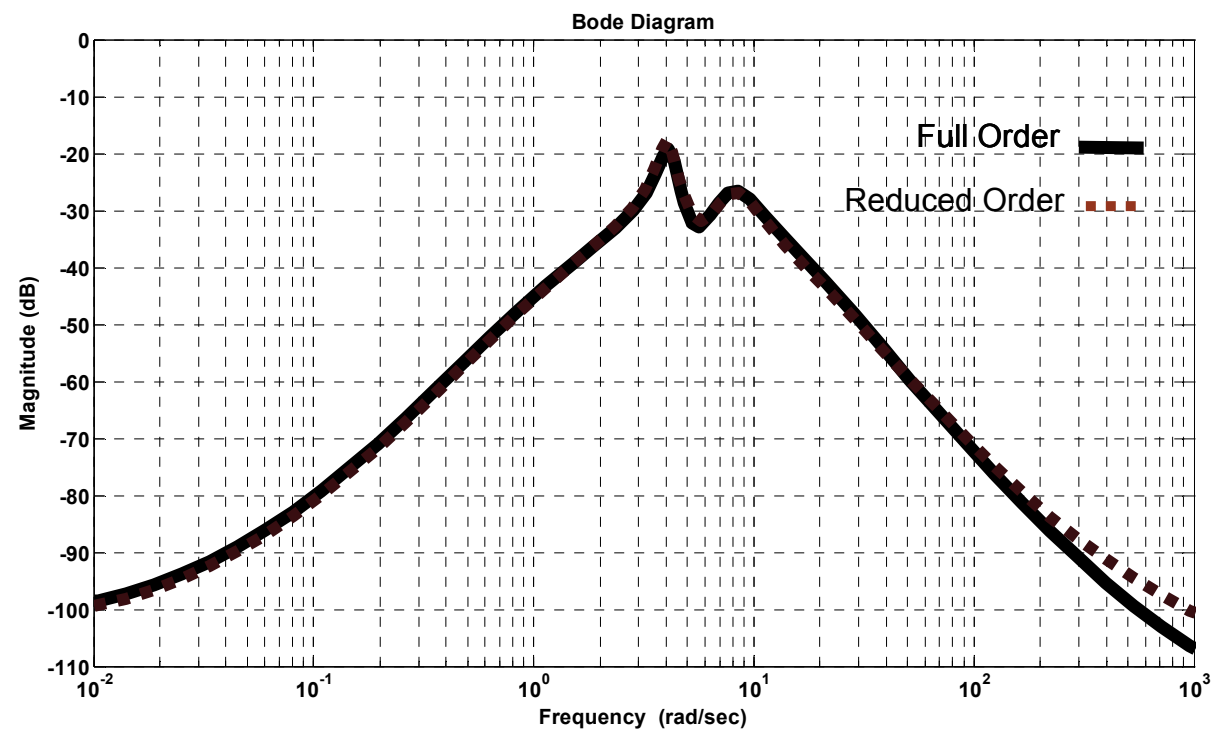

Fig. 7. Frequency response of full and reduced order model of the studied network

\subsection{Modal analysis}

In the section, the modal analysis is performed to determine critical modes in different power transmission levels between areas to investigate the proposed controller performance. The previous determined critical modes and their new damping ratios at two different power levels between TREC to EREC and KhREC regions, given in Table 4, show that the damping of the critical modes is increased significantly. The robustness of the proposed method is also veryfied in different contingencies at a 2000 MVA power transmission level between areas. The critical inter-area mode damping is improved considerably at different system conditions such as an outage of a $400 \mathrm{kV}$ line as shown in Table 5.

Table 3. Margin values of time delays with different choices for $W_{2}$

\begin{tabular}{c|c}
\hline \multirow{2}{*}{ Robust controller } & Delay margin in msec \\
\cline { 2 - 2 } & $\mu=0$ \\
\hline constant $W_{2}$ & 269.2 \\
\hline proposed $W_{2}$ & 512 \\
\hline
\end{tabular}

Table 4. Critical modes and related damping ratios at different transmission level

\begin{tabular}{c|c|c|c|c}
\hline \multirow{2}{*}{$\begin{array}{c}\text { Mode } \\
\text { index }\end{array}$} & \multicolumn{2}{|c|}{ Designed controller in 1600 MVA } & \multicolumn{2}{c}{ Designed controller in 2000 MVA } \\
\cline { 2 - 5 } & $\xi$ & $f(\mathrm{~Hz})$ & $\xi$ & $f(\mathrm{~Hz})$ \\
\hline 1 & 0.216 & 0.742 & 0.211 & 0.749 \\
\hline 2 & 0.134 & 0.532 & 0.128 & 0.536 \\
\hline 3 & 0.197 & 0.554 & 0.204 & 0.547 \\
\hline 4 & 0.237 & 0.487 & 0.232 & 0.492 \\
\hline
\end{tabular}


Table 5. Critical modes and related damping ratios in different contingencies in 2000 MVA power transmission

\begin{tabular}{c|c|c|c|c|c|c}
\hline \multirow{2}{*}{$\begin{array}{c}\text { Mode } \\
\text { index }\end{array}$} & \multicolumn{2}{|c|}{ Line 36-20 out } & \multicolumn{2}{c|}{ Line 3-20 out } & \multicolumn{2}{c}{ Line 1-51 out } \\
\cline { 2 - 7 } & $\xi$ & $f(\mathrm{~Hz})$ & $\xi$ & $f(\mathrm{~Hz})$ & $\xi$ & $f(\mathrm{~Hz})$ \\
\hline 1 & 0.207 & 0.735 & 0.194 & 0.697 & 0.197 & 0.691 \\
\hline 2 & 0.151 & 0.474 & 0.116 & 0.498 & 0.123 & 0.526 \\
\hline 3 & 0.185 & 0.534 & 0.207 & 0.475 & 0.202 & 0.529 \\
\hline 4 & 0.218 & 0.499 & 0.227 & 0.503 & 0.215 & 0.477 \\
\hline
\end{tabular}

\subsection{Time domain simulation}

The proposed method is applied in the allocated UPFC and its performance is verified through time domain simulation. The $100 \mathrm{~ms}$ delay time is specified as a normal situation. The Digsilent Power Factory software is used to time domain simulation of the interconnected power system at the 2000 MVA (peak loading condition) power transmission from TREC to another two areas, which in normal condition results in unstable oscillation in contingencies between areas. To show the effectiveness of the proposed method, the dynamic response of the system is compared with the $H_{\infty}$ designed damping controller and no damping controller condition (only series and shunt PI controllers).

Case1. In this case, the three phase short circuit with zero fault impedance is applied to bus 1 at $t=0.1 \mathrm{~s}$. The fault is removed $200 \mathrm{~ms}$ later, without network topology being changed.

The G1 (from TREC area) rotor angle and its active power variation, using different control methods, are depicted in Figs. 8 and 9. In addition, the G13 generator (from KhREC area) rotor angle is shown in Fig. 10 at this condition. Thus, when there is no supplementary controller, the system stability is lost, due to unstable inter-area oscillations. While, by applying the proposed method, the network stability is increased significantly and oscillations are damped out properly. Also, the proposed method has a better dynamic response comparing with the $H_{\infty}$ method, as shown in Figs. 8-10.

To show the robustness and effectiveness of the proposed method, its performance is demonstrated at two different 200 and $300 \mathrm{~ms}$ time delays, compared with no time delay in Fig. 11. The oscillations are damped out properly at different time delays, which makes the proposed algorithm more effective in real practical wide area application in power systems. As shown in Fig. 12, the designed algorithm presents acceptable dynamic response, even in $500 \mathrm{~ms}$ time delay for this case.

The voltage magnitude of the UPFC DC bus following this disturbance is shown in Fig. 13.

Case 2. In this case, both of network operating point and applied disturbance are changed to investigate the dynamic performance of the proposed method, at different conditions. It is assumed that at a 1400 MVA power transmission level (off-peak loading condition) from northern areas to southern areas, a single phase to ground fault is occurred in lines 20-36 at $t=100 \mathrm{~ms}$. 


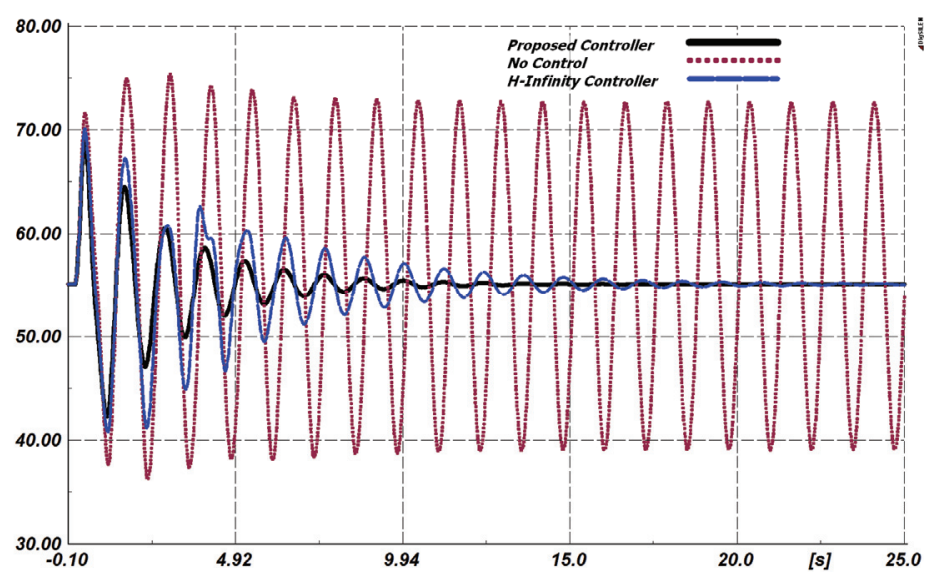

Fig. 8. G1 rotor angle variation in degrees, using different methods

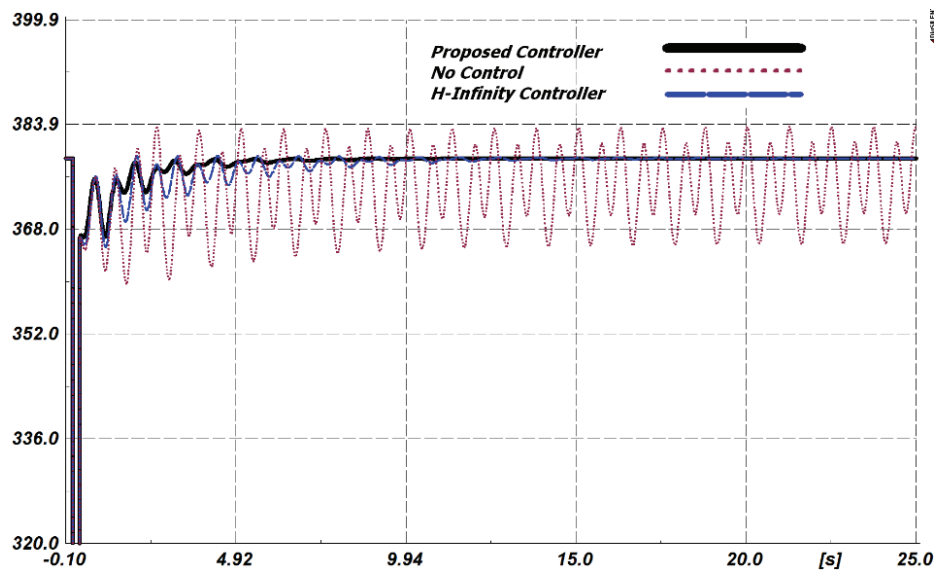

Fig. 9. G1 active power variation in MW using different methods

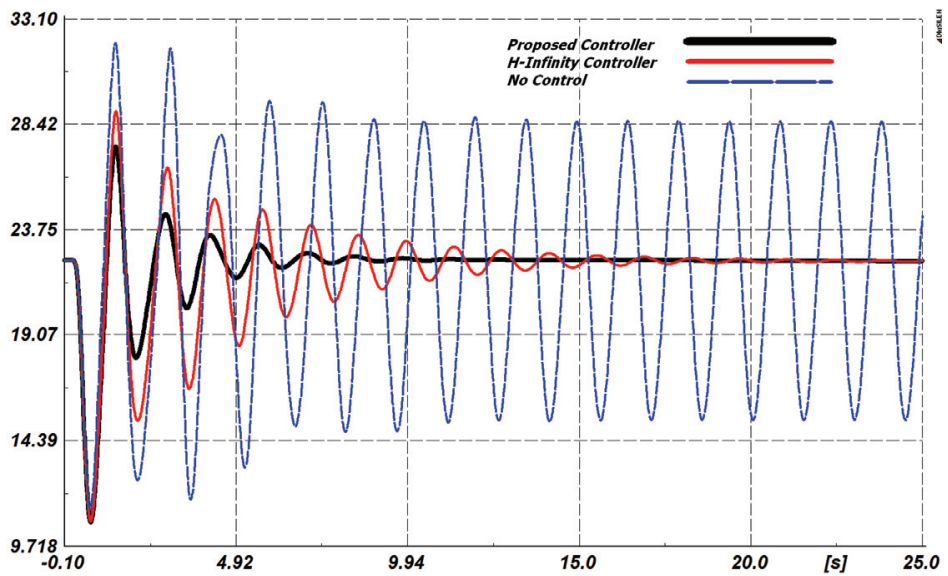

Fig. 10. G13 rotor angle variation in degrees, using different algorithm 
Vol. 66 (2017) Optimal robust stabilizer design based on UPFC for interconnected power systems

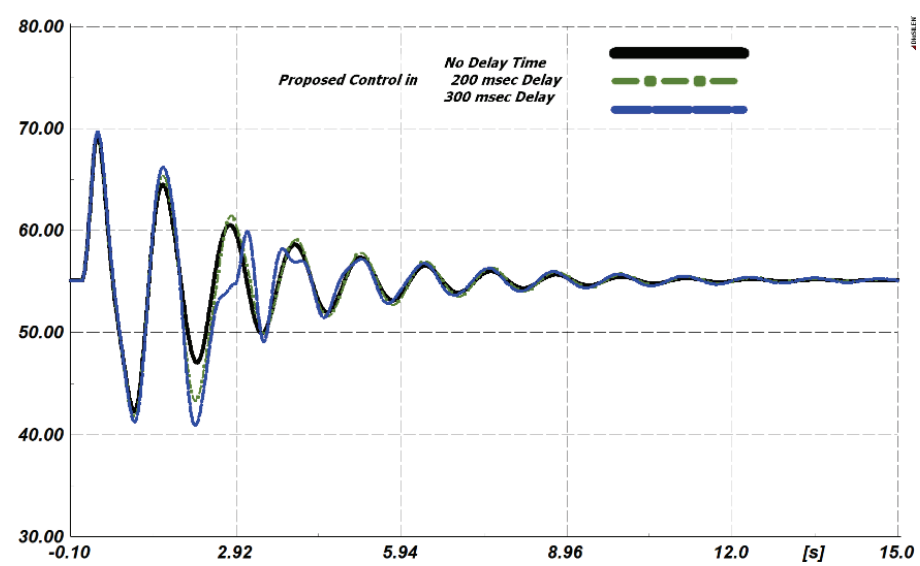

Fig. 11. G1 rotor angle variation in degrees, using the proposed controller with different time delays

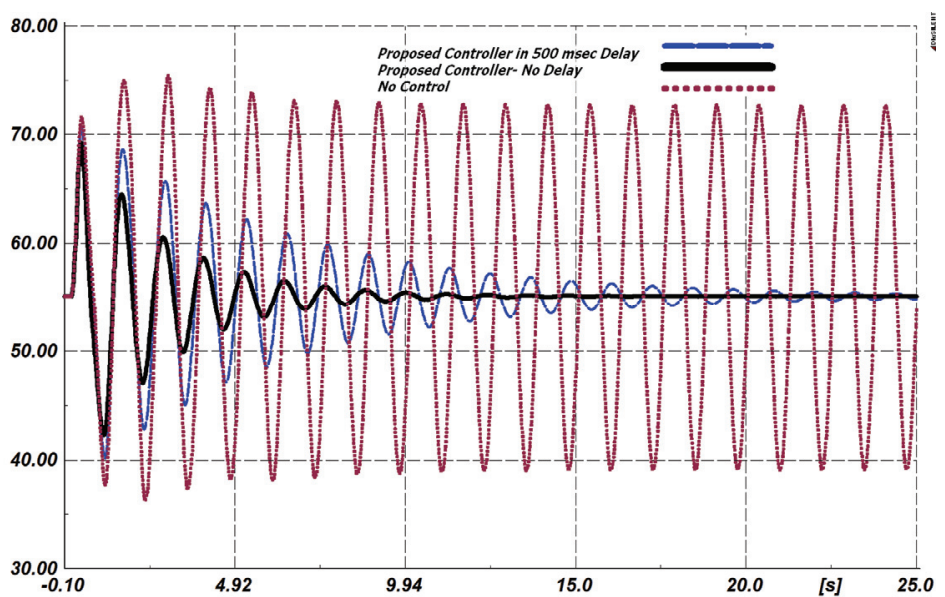

Fig. 12. G1 rotor angle variation in degrees, using the propose method with $500 \mathrm{~ms}$ time delay

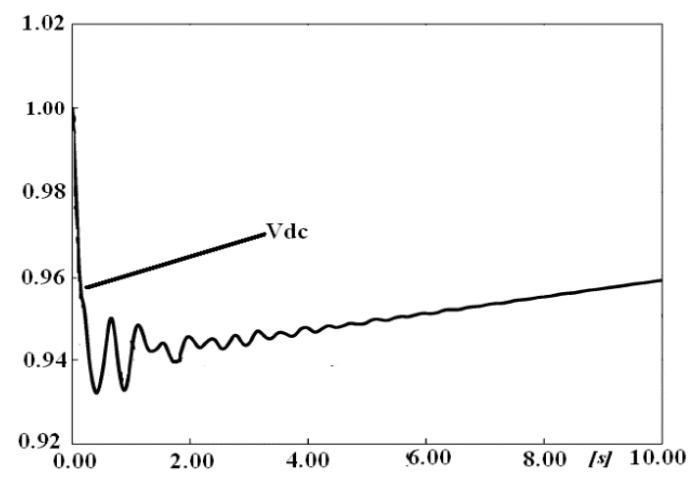

Fig. 13. The UPFC DC voltage variation in pu in case 1 
The fault is removed by opening the related line circuit breakers, $150 \mathrm{~ms}$ later at $t=250 \mathrm{~ms}$. The $\mathrm{G} 7$ generator (from E.R.E.C area) rotor angle and active power variation, using different control methods, are shown in Figs. 14 and 15. The time delay in this case is considered to be $200 \mathrm{~ms}$. In this case, the damping of oscillation increased with the application of the proposed method. Therefore, it can be concluded that the proposed method increased the damping of oscillations at different operating points.

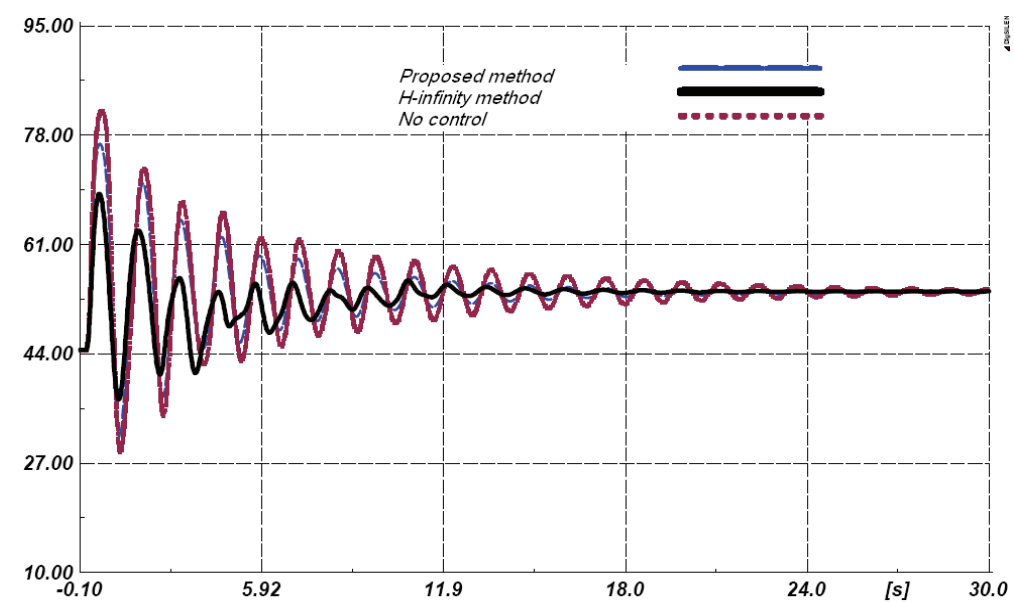

Fig. 14. G7 rotor angle variation in degrees at different controller methods in case 2

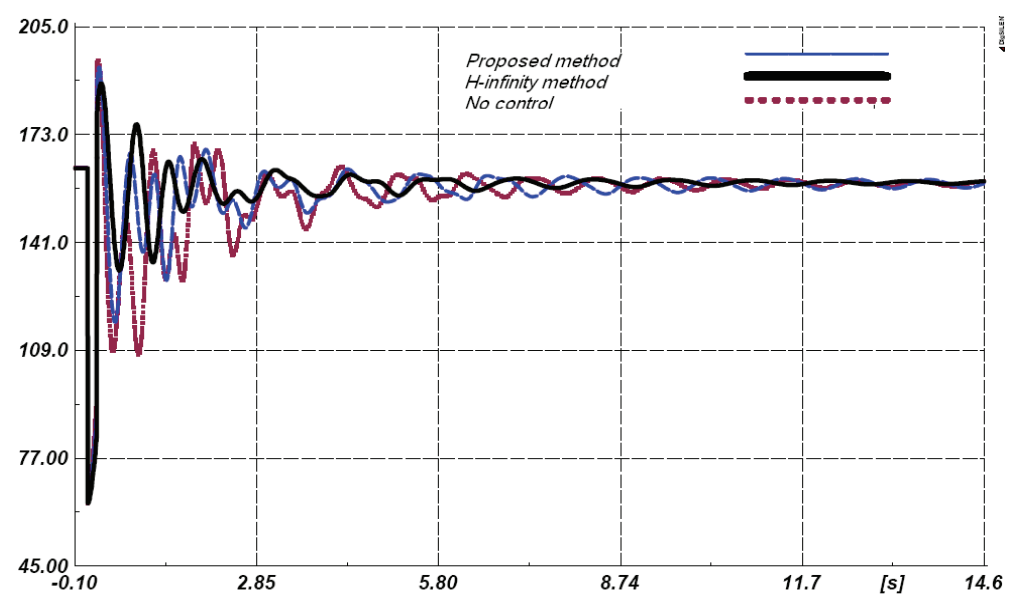

Fig. 15. G7 active power variation in MW, using different control methods in case 2

Case 3. In order to evaluate the system response to small disturbances, the +0.05 pu step change is applied to the mechanical power of the G7 from the EREC network. The G7 rotor angle variation under different control conditions is shown in Fig. 16. The proposed method performance is significantly better than two other methods. 


\section{Conclusions}

In this paper, a new wide area optimal controller based on the mixed $\mathrm{H}_{2} / \mathrm{H}_{\infty}$ method for the supplementary damping controller for the allocated UPFC has been presented. To achieve an optimal damping performance, the regional pole placement is applied and the output feedback controller is determined by the LMI approach. Wide area measurement signals have been selected optimally by using the geometric analysis in the full order model. The time delay margins for the proposed method are determined with respect to constant time delay and different weighting functions. The proposed method is applied in the large multi-machine interconnected power system from the IRAN power grid with its practical damping problems. The small signal stability analysis and time domain simulation show that system stability and dynamic performance is improved at different conditions and disturbances by the proposed method.

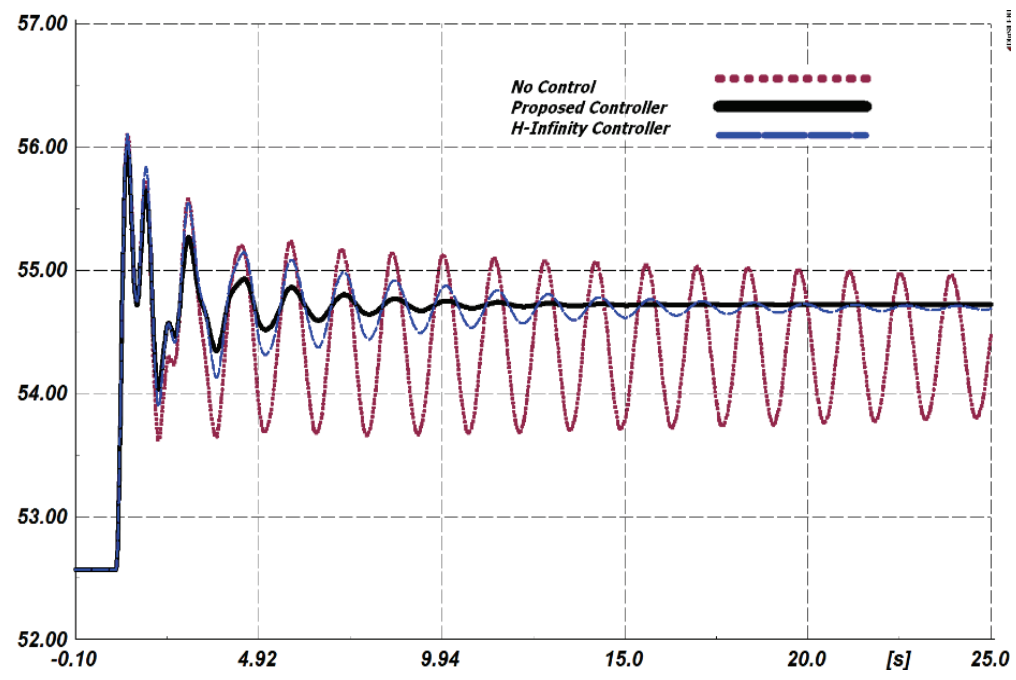

Fig. 16. G7 rotor angle variation in degrees in case 3

\section{References}

[1] Kundur P., Power System Stability and Control, McGraw-Hill, New York (1994).

[2] Hemmati R., Koofigar H.R., Ataei M., Optimal adaptive controller based on STATCOM and $U P F C$, Journal of Electrical Engineering and Technology, vol. 11, no. 5, pp. 1057-1062 (2016).

[3] Hingorani N.G., Gyugyi L., Understanding FACTS: Concepts and Technology of Flexible AC Transmission Systems, IEEE Press, New York (2000).

[4] Marjanain A., Jafari E., Barati H., Designing of a TEF-based neuro-fuzzy controller for IPFC to improve the transient stability, International Transactions on Electrical Energy Systems, vol. 23, no. 6, pp. 818-834 (2013).

[5] Ma T.T., Lo K.L., Tumay M., A robust UPFC damping control scheme using PI and ANN based adaptive controllers, COMPEL - The international journal for computation and mathematics in electrical and electronic engineering, vol. 19, no. 3, pp. 878-902 (2000). 
[6] Khan L., Lo K.L, Jovanovic S., Hybrid GA neuro-fuzzy damping control system for UPFC, COMPEL, The international journal for computation and mathematics in electrical and electronic engineering, vol. 25, no. 4, pp. 841-861 (2006).

[7] Padiyar K.R., Saikumar H.V., Coordinated design and performance evaluation of UPFC supplementary modulation controllers, International Journal of Electrical Power and Energy Systems, vol. 27, no. 2, pp. 101-11 (2005).

[8] Mehraeen S., Jagannathan S., Crow M.L., Novel dynamic representation and control of power systems with FACTS devices, IEEE Transaction on Power Systems, vol. 25, no. 3, pp. 1542-1554 (2010).

[9] Pal B.C., Robust damping of inter area oscillations with unified power flow controller, IEE Proceedings Generation, Transmission and Distribution, vol. 149, no. 6, pp. 733-738 (2002).

[10] Parniani M., Iravani M., Optimal robust control design of static VAR compensators, IEE Proceedings Generation, Transmission and Distribution, vol. 145, no. 3, pp. 301-307 (1998)

[11] Majumder M., Chaudhuri B., El-Zobaidi H., Pal B.C., Jaimoukha I.M., LMI approach to normalized $H_{\infty}$ loop-shaping design of power system damping controllers, IEE Proceedings Generation, Transmission and Distribution, vol. 152, no. 6, pp. 952-960 (2005).

[12] Scherer C., Gahinet P., Chilali M., Multi objective output feedback control via LMI optimization, IEEE Transactions on Automation Control, vol. 42, no. 7, pp. 896-911 (1997).

[13] Farsangi M., Song Y., Tan M., Multi-objective design of damping controllers of FACTS devices via mixed $\mathrm{H}_{2} / \mathrm{H}_{\infty}$ with regional pole placement, International Journal of Electrical Power and Energy Systems, vol. 25, no 5, pp. 339-46 (2003).

[14] Zhang Y., Bose A., Design of wide-area damping controllers for inter area oscillations, IEEE Transactions on Power Systems, vol. 23, no. 3, pp. 1136-1143 (2008).

[15] Zhang C.K., Jiang L., Wu Q.H., et al., Delay-dependent robust load frequency control for time delay power systems, IEEE Transactions on Power Systems, vol. 28, no. 3m, pp. 2192-2201 (2013).

[16] Wu H., Tsakalis K., Heydt G., Evaluation of time delay effects to wide area power system stabilizer design, IEEE Transaction on Power Systems, vol. 19, no. 4, pp. 1935-1941 (2004).

[17] Dong L., Zhang L., Crow M., A new control strategy for the unified power flow controller, Proceedings of IEEE PES Winter Meeting, pp. 562-566 (2002).

[18] Zhou K., Doyle J.C., Glover K., Robust and Optimal Control, Prentice Hall, New Jersey (1995).

[19] Gahinet P., Apkarian P., A linear matrix inequality approach to control, International Journal of Robust Nonlinear Control, vol. 4, no. 4, pp. 421-448 (1994).

[20] Boyd S., Ghaoui L., Feron E., Balakrishnan V., Linear Matrix Inequalities in System and Control Theory, SIAM, Philadelphia (1994).

[21] MATLAB toolbox, Mathpower (2008).

[22] Yao W., Jiang L., Wu Q., Wen J.Y., Cheng S.J., Delay-dependent stability analysis of the power system with a wide-area damping controller embedded, IEEE Transactions on Power Systems, vol. 26, no. 1, pp. 233-240 (2011).

[23] Xu S.Y., Lam J., On equivalence and efficiency of certain stability criteria for time-delay systems, IEEE Transaction on Automatic Control, vol. 52, no. 1, pp. 95-101 (2007).

[24] Wu M., He Y., She J.H., Liu G.P., Delay-dependent criteria for robust stability to time-varying delay systems, Automatica, vol. 40, no. 8, pp. 1435-1439 (2004).

[25] Jiang L., Yao W., Wu Q.H., Wen J.Y., Cheng S.J., Delay-dependent stability for load frequency control with constant and time-varying delays, IEEE Transactions on Power Systems, vol. 27, no. 2, pp. $932-941$ (2012).

[26] Heniche A., Kamwa I., Control loops selection to damp inter area oscillations of electrical networks, IEEE Transaction on Power Systems, vol. 17, no. 2, pp. 378-384 (2002).

[27] Ghahinet P., Nemirovski A.J., Chilali M., LMI Control Toolbox User Guide, Matworks (1995).

[28] E.R.E.C planning group, IGMC planning study in IRAN national power grid in 2012 (2012).

[29] Thukaram D., Jenkins L., Visakha K., Improvement of system security with unified power flow controller at suitable locations under network contingencies of interconnected systems, IEE Proceedings Generation, Transmission and Distribution, vol. 151, no. 5, pp. 682-690 (2005). 